Marquette University

e-Publications@Marquette

College of Education Faculty Research and

Publications

Education, College of

$1-1-2009$

\title{
A Brief Version of the Family Background Questionnaire
}

Timothy P. Melchert

Marquette University, timothy.melchert@marquette.edu

Augustine Kalemeera

Marquette University

Published version. Measurement and Evaluation in Counseling and Development, Volume 41, No. 4 (January 2009). Publisher Link. Reprinted from Measurement and Evaluation in Counseling and Development, Vol. 41, January 2009, p. 210. (c) 2009 The American Counseling Association.

Reprinted with permission. No further reproduction authorized without written permission from the American Counseling Association. 


\title{
A Brief Version of the Family Background Questionnaire
}

\author{
Timothy P. Melchert and Augustine Kalemeera
}

\begin{abstract}
Although it is lengthy, the Family Background Questionnaire provides reliable behaviorally specific family history information. Results from reliability and validity analyses suggest that a brief version of this instrument that assesses parental responsiveness, child maltreatment, and parental substance abuse would provide a useful screening instrument for obtaining family history information.
\end{abstract}

T: he influence of childhood experiences on an individual's psychosocial development remains one of the most important areas of research and clinical interest in psychology. Whereas a range of psychological, biological, and social factors influence psychosocial development and adjustment, researchers have viewed the family as the "primary arena" in which children's socialization and personality development take place (Maccoby, 1984, p. 318). Therefore, assessment of an individual's childhood and family of origin experiences can be crucial for understanding that person's development and current functioning. Although retrospectively measuring characteristics of childhood and family of origin experiences is obviously not possible, obtaining information regarding how adults remember and perceive their family of origin experiences is useful for many purposes. As a result, efficient assessment instruments are needed for obtaining family history information.

Although interview-based family history assessments are better suited for obtaining detailed and specific family history information, questionnaire methods are usually more time efficient; consequently, a variety of questionnaire instruments have been developed to assess characteristics of an individual's family of origin (for reviews, see Melchert, 1998a; Touliatos, Perlmutter, \& Straus, 2001). These instruments include a broad range of variables and approaches, some focused on relatively global judgments about the qualities of respondents' family experiences (e.g., the Parental Bonding Instrument by Parker, Tupling, \& Brown, 1979, includes items such as "[My parent] did not want me to grow up" and "[My parent] was overprotective of me") and others focused on relatively specific family characteristics that respondents may have had (e.g., the Schwarz-Getter Interparental Conflict Scale; Schwarz \& Zuroff, 1979). One of the instruments designed to provide a comprehensive and relatively behaviorally specific assessment of family history is the Family Background Questionnaire (FBQ; Melchert \& Sayger, 1998). The original version of this instrument is lengthy (179 items), assessing a wide range of family characteristics. The 22 subscales in the original FBQ include items concerning the various forms of child abuse and neglect, style of behavioral control and expression of affect within the family, parental substance abuse and psychological adjustment, and major stressors that a family may have experienced.

A shorter version of the original FBQ would be more useful for many clinical and research purposes. Therefore, we undertook the present study to develop a brief version that would

Timothy P. Melchert and Augustine Kalemeera, both at Department of Counseling and Educational Psychology, Marquette University. Augustine Kalemeera is now at Catholic Charities, Milwaukee, Wisconsin. Correspondence concerning this article should be addressed to Timothy P. Melchert, Department of Counseling and Educational Psychology, Marquette University, 168F Schroeder Complex, Milwaukee, WI 53201-1881 (e-mail: timothy.melchert@marquette.edu). 
incorporate recent research and theoretical developments in the field and that would maintain the original instrument's reliability and validity. Before introducing the brief version, we review the theoretical rationale for both the original and brief versions of the FBQ. Then we describe the procedures used to develop the brief FBQ. Finally, we compare the results of the reliability, factor structure, and other analyses of the brief version of the instrument with those of the original $\mathrm{FBQ}$.

\section{THEORETICAL RATIONALE FOR THE ORIGINAL FBQ}

The original FBQ was developed to provide a relatively behaviorally specific approach to measuring a broad range of family of origin characteristics (Melchert \& Sayger, 1998). Although some items ask for judgments about various aspects of respondents' relationships with their parents and other factors (e.g., "I felt that my mother and father loved me"), most items focus on more specific behaviors that respondents experienced within their families (e.g., "My mother and father told me that they loved me" with frequency options ranging from Never to At least once a month). The theoretical rationale for the original instrument was developed on the basis of a comprehensive review of the literature on child development, with subscales being included if significant research existed that supported the importance of particular influences on family functioning and child development. As a result, the original FBQ includes 22 subscales covering parental responsiveness (vs. emotional neglect), parental acceptance (vs. emotional abuse), parental physical abuse, physical neglect, sexual abuse, parental educational involvement, parental decision-making style, level of emotional expression in the family, style of behavioral control, number and range of chores performed, parental substance abuse, parental psychological adjustment, nature of the parental coalition, level of child social support (vs. isolation), and level of family stressors. Of the 22 subscales, 14 measure mother and father behavior separately, and all but the Chores subscale are scored so that higher scores indicate higher family functioning (the Chores subscale simply reflects the number and range of chores performed).

The behaviorally specific approach of the FBQ required that most items inquire about mother and father behavior separately, and response options for approximately one half of the items refer to specified frequencies or durations (e.g., Never to 3 or more times a week in comparison with Almost never to Almost always). Several indications exist that the resulting instrument is reliable and valid. The internal consistency reliability of the original FBQ has been found to be adequate to very strong (with Cronbach alpha coefficients ranging from .76 to .96 for the subscales and .98 for the Total Scale; Melchert \& Sayger, 1998). Support for its validity includes the results from an evaluation by expert judges, a factor analysis, correlations between siblings from the same families, and patterns of scores between various clinical and nonclinical groups and between groups reporting various types of child abuse histories (Melchert, 1998b; Melchert \& Sayger, 1998). Although the original FBQ is among the most comprehensive and behaviorally oriented of the instruments that assess family history with adults (Melchert, 1998a), its length makes it impractical for many research and clinical purposes in which brief measures are needed.

\section{THEORETICAL RATIONALE FOR THE REVISED AND SHORTENED VERSION OF THE FBQ}

Despite its strengths, for some purposes the original FBQ is unwieldy in terms of the time needed for administration and demands placed on respondents for completing the rather 
lengthy instrument. Whereas a brief version of the FBQ that assesses a subset of the constructs included in the original FBQ would result in greater clinical utility, it would also result in restricted coverage of the full range of aspects of family functioning included in the original instrument. A reduction in construct representativeness might be justified if a shorter version would assess the most important aspects of family functioning. Therefore, our highest priority in developing a shorter instrument was to ensure that the aspects of family functioning that seem to have the greatest effect on children's development and functioning were retained. The literature review that led to the development of the original FBQ's subscales suggested that some family variables exert greater influence over children's development. We made our decision about which variables to retain in the FBQ-Brief (FBQ-B) on the basis of the original literature review and a review of the current research examining family influences on children's development. We also wanted to ensure that the FBQ-B was consistent with recent research and theoretical developments regarding the influence of families on development. Three areas of family functioning have received perhaps the greatest research and clinical attention in terms of their influence on psychological adjustment and personality development: parental responsiveness, child maltreatment, and parental substance abuse.

The effects of different approaches to parental responsiveness have long been a central focus of psychological research and practice ever since Freud brought attention to this area more than a century ago. Maccoby (e.g., 1984) conducted some of the most comprehensive reviews of the research examining the effects of different approaches to parental responsiveness on children's development and adjustment. Since then, a great deal of research in this area has been done in the context of attachment theory (e.g., see Grossmann, Grossmann, \& Waters, 2006; Mikulincer \& Shaver, 2007). A review of this research finds that parenting approaches characterized by consistent, sensitive, supportive, and accepting responsiveness are frequently associated with positive outcomes across a wide variety of domains including emotional and behavioral regulation, interpersonal regulation, relationship functioning, and psychopathology. The findings of recent research in this area support the conclusions reached in the original conceptualization of the FBQ regarding both the importance given to parental responsiveness as well as the manner in which it was conceptualized.

In contrast to the long-standing interest in the effects of different levels of parental responsiveness, little professional attention had been paid to child maltreatment before the pediatrician Henry Kempe and his colleagues published their observations regarding the battered child syndrome (Kempe, Silverman, Steele, Droegemueller, \& Silver, 1962). Thereafter, concern about child physical abuse increased rapidly, and a large amount of research subsequently investigated the prevalence of the major forms of maltreatment, their consequences for development and adjustment, and their prevention and treatment (as reflected in the emergence in recent decades of journals such as Child Abuse \& Neglect, Child Abuse Review, Child Maltreatment, Journal of Child Sexual Abuse, Journal of Emotional Abuse, Journal of Family Violence, and Journal of Interpersonal Violence).

Although our focus is primarily on family of origin influences on child maltreatment, these influences do take place within a broader context. For this reason, the basis of most current approaches to understanding child maltreatment is an integrative systemic perspective. Bronfenbrenner (1979) proposed what may be the most fully elaborated ecological or systemic approach to explaining child development, and Belsky (1980) applied this model specifically to child maltreatment. The model incorporated four main levels of interacting influences (ontogenic or organismic influences, microsystem or family influences, exosystem or work and neighborhood influences, and macrosystem or larger societal and cultural influences). Cicchetti and Lynch (1993) further elaborated on Belsky's model, adding a transactional perspective 
that focused on the developmental outcomes for children who experienced maltreatment. This ecological-transactional framework more effectively captures the complex interactions among the many psychological, family, and sociocultural influences on child development and has become the dominant approach for understanding child maltreatment (Scannapieco \& Connell-Carrick, 2005).

Research has consistently found that most maltreatment occurs within the family. For example, the Third National Incidence Study of Child Abuse and Neglect (Sedlak \& Broadhurst, 1996a) found that the large majority of maltreated children (78\%) were maltreated by their birth parents. Among maltreated children in general, birth parents were more likely to have neglected their children (91\%) than to have abused their children (62\%). Sexual abuse followed a different pattern. According to the authors, birth parents were found to be the perpetrators in approximately one quarter of the cases, and nearly half of the sexually abused children were sexually abused by someone other than a birth parent or parent: substitute.

Definitions of child physical abuse, physical neglect, and sexual abuse have remained relatively stable over recent decades. Psychological maltreatment has also long been of concern, but the construct has been more difficult to define, and signs and indications of this form of maltreatment have been more difficult to identify. Nonetheless, substantial progress has been made in this area as well. When the original FBQ was being developed, terms such as emotional abuse and neglect were commonly used to explain parents' psychologically damaging acts toward their children (e.g., National Center on Child Abuse and Neglect, 1981). Since then, psychological maltreatment has become the generally preferred term because it is inclusive regarding both the cognitive and affective aspects of maltreatment as well as the perpetration of acts of commission and omission (Hart, Brassard, Binggeli, \& Davidson, 2002).

The original FBQ includes a subscale for parental educational involvement (vs. educational neglect) because of the substantial evidence supporting the positive influence of parents' involvement in their children's education. As a result, major stakeholders in the field such as the U.S. Department of Health and Human Services (e.g., National Center on Child Abuse and Neglect, 1981) included educational neglect as one of the main categories of child maltreatment. Since then, however, a number of questions regarding this conceptualization have not been satisfactorily resolved. Consensus regarding legal, policy, and research definitions has not developed, and educational neglect has not emerged as a separate category in most current approaches to child maltreatment (e.g., Erickson \& Egyeland, 2002; Scannapieco \& Connell-Carrick, 2005). Although the importance of this variable is not in dispute, no consensus exists regarding its inclusion as a form of child maltreatment. Consequently, we did not include the parental educational involvement subscale in the FBQ-B.

Because of this evolution of theory and research on child maltreatment, we combined in the FBQ-B the original FBQ's parental responsiveness and parental acceptance subscales into one parental responsiveness subscale (with psychological maltreatment representing the negative end of the continuum). In addition, we retained the parental physical abuse, physical neglect, and sexual abuse subscales as they were originally conceptualized.

Parental substance abuse is the third area of inquiry retained in the FBQ-B. Substance dependence is the most frequently diagnosed mental disorder in males and one of the most frequently diagnosed in females (Substance Abuse and Mental Health Services Administration, 2007). Substance dependence has also been found to be one of the most important risk factors for family dysfunction in general and child maltreatment specifically (e.g., Kelley, 2002; Reid, Macchetto, \& Foster, 1999; Sedlak \& Broadhurst, 1996b). After reviewing the available data from child welfare agencies and from self-report community samples, Wekerle and Wall (2002) concluded that at least $40 \%$ of child-abusing parents also had alcohol or drug 
problems. Because of its prevalence and significance as a risk factor for family dysfunction, we retained the parental substance abuse subscale from the original FBQ.

In summary, of the 22 subscales of the original FBQ, 10 were retained for the FBQ-B including parental responsiveness and parental acceptance (combined to create a single construct of responsiveness), parental physical abuse, physical neglect, sexual abuse, and parental substance abuse. Of these, all but the physical neglect and sexual abuse subscales assess mother and father behavior separately, resulting in 8 subscales for the FBQ-B. These subscales reflect the importance of parental responsiveness, child maltreatment, and parental substance abuse on children's development, as consistently shown in the research.

\section{METHOD}

\section{Participants}

The study sample was recruited from three campuses of an urban technical college system in the upper Midwest. A total of 394 students participated in the study; however, 10 of the questionnaires returned were not adequately completed, resulting in usable data from 384 respondents. More than half of the respondents (62\%) were female students. Regarding ethnic heritage, $51 \%$ of the sample indicated European American, 28\% African American, $6 \%$ Hispanic American, 3\% Asian American, 2\% Arab American, 2\% Native American, 4\% Other, and $4 \%$ did not indicate ethnicity. The ages of the respondents ranged from 18 years to 60 years, with the mean age of 25.70 years $(S D=8.54)$.

\section{Instruments}

$F B Q-B$. Whereas the original version of the FBQ includes 179 items and 22 subscales (Melchert $\&$ Sayger, 1998), the brief version (FBQ-B) includes 68 items distributed across 8 subscales. Of these 68 items, 60 result from 30 stems that ask for separate responses for mothers and fathers (i.e., an item stem is followed by separate mother and father response options). Thus, the FBQ-B includes 38 questions/statements. All items are scored so that higher scores indicate higher levels of family functioning. With the exception of most of the Sexual Abuse subscale items, the FBQ-B items use a 5-point response scale. The original FBQ's Mother and Father Responsiveness and Mother and Father Acceptance subscales have been retained but are combined in the FBQ-B to create the revised Mother and Father Responsiveness subscales.

In its present form, the FBQ-B includes items representing eight subscales: Mother and Father Responsiveness (psychological maltreatment at the low end of the continuum vs. warm and sensitive approval, attentive listening, and support at the high end), Mother and Father Physical Abuse (violent, physically injurious behavior at the low end vs. the absence of these behaviors at the high end), Physical Neglect (the lack of appropriate food, shelter, clothing, supervision, and care when ill or injured at the low end vs. their provision at the high end), Sexual Abuse (sexual contact by parents, other relatives, or nonrelatives at the low end vs. their absence at the high end), and Mother and Father Substance Abuse (higher frequency of intoxication and problems caused by drinking or drug use, along with suspected alcoholism or addiction at the low end vs. their absence at high end). In addition, the Total Scale score represents the mean score across items from all the subscales, providing an estimate of the overall level of family functioning.

A global item asking for the respondent's perspective on the level of emotional, physical, or sexual abuse experienced has been added to each of the Mother and Father Responsiveness, 
Mother and Father Physical Abuse, and Sexual Abuse subscales, respectively. For example, "Do you consider yourself to have been sexually abused as a child?" with response options including No; Yes, but it was minor; Yes, mildly; Yes, moderately; and Yes, severely has been added as an item in the Sexual Abuse subscale. The basis for the rationale for adding these global items is the research by Widom and Morris (1997) that found that adults' self-reports regarding whether they considered themselves to have been sexually abused as children were somewhat more consistent with the juvenile and criminal records from their childhoods documenting sexual abuse than were other types of questions asking about sexually abusive childhood experiences. To extend the assessment of the severity of physical abuse, two item stems with separate mother and father response options have been added to the Mother and Father Physical Abuse subscales (i.e., "How often did your mother and father beat or hit you with their hands or a fist?" and "How often did your mother and father hurt you so badly that you needed medical treatment?"). In addition, the response options have been changed for the Sexual Abuse subscale items that assess frequency of abuse (i.e., all the Sexual Abuse subscale items other than the new global item regarding the level of abuse). Instead of the original FBQ's 5-point response options (i.e., None, Once, 2 to 5 times, 6 to 19 times, and 20 or more times), the FBQ-B provides Yes and No options followed by the question, "If 'Yes,' how many times?" Feedback from respondents has suggested that the original FBQ's response scale has caused some uneasiness because one person who experienced a single highly abusive and traumatic event could receive what was sometimes perceived as a "lower" score than other people who experienced several abusive events that they considered to be only mildly abusive. More precise frequency information could also be obtained through the new response format.

It is also important to note that the Sexual Abuse subscale items do not function as a scale, neither in the original FBQ nor in the FBQ-B. Most of these items ask about childhood sexual contact with different categories of persons (e.g., mothers, fathers, other relatives, nonrelatives) and are not designed to measure a unitary construct (e.g., sexual contact with one parent is not necessarily associated with experiencing sexual contact with the other parent, other relatives, or nonrelatives; a high score on one item is not predictive of high scores on the other items). Instead, these items are designed to function as a checklist regarding different types of sexually abusive childhood experiences.

Most of the items from the original FBQ's selected subscales have been retained verbatim; however, 11 items have been deleted to shorten the FBQ-B. Item-total correlations were used to identify those items that could be deleted from the FBQ-B without sacrificing its reliability. Thus, the items with similar content to others and with the lowest correlations between individual items and their respective subscales have been deleted. The item-total correlations were greater than .40 for all items retained with one exception. A lower cutoff of .30 was used with an item stem from the Mother and Father Physical Abuse subscales so that these infrequently endorsed items, which nonetheless represent an important aspect of the construct being assessed, could be retained (i.e., "How often did your mother and father hurt you so badly that you needed medical treatment?" is considered important for assessing physical abuse even though the item-total correlations were .38 for mothers and .31 for fathers).

Center for Epidemiologic Studies Depression Scale (CES-D). The CES-D (Radloff, 1977) is used to measure depressive symptomatology. Internal consistency reliability estimates have been found to range from .85 to .90 , and test-retest reliability coefficients have ranged from .51 to .67 over intervals of 2 to 8 weeks. Validation studies have found that the CES-D has high sensitivity and satisfactory specificity. The original version of the instrument includes 20 items, but the shorter 9-item version was used in this study. This shorter version has been found to correlate at greater than .80 across samples with the original version and have com- 
parable accuracy in terms of classifying cases with depressive symptoms (Santor \& Coyne, 1997). In the present study, the Cronbach alpha coefficient was .81 .

Costello-Comrey Anxiety Scale (CCAS). The CCAS (Costello \& Comrey, 1967) is a 9-item scale that has been found to have split-half and test-retest reliability coefficients of .70 and .72 , respectively. Validity studies have indicated that scores on the instrument correlate highly with other anxiety scales and discriminate between clients groups rated high and low in anxiety by their psychiatrists. In the present study, the Cronbach alpha coefficient was .85 .

Aggression Questionnaire (AQ) Hostility subscale. The AQ (Buss \& Perry, 1992) is a 29-item instrument designed to measure four aspects of aggression; however, only the 8-item Hostility subscale was used in this study. The Cronbach alpha coefficient for the AQ Hostility subscale has been found to be .77 and the 9-week test-retest reliability coefficient has been found to be .72. Support has been found for a variety of forms of validity evidence including significant correlations between AQ scores and peer observations of aggression, sociability, and shyness. In this study, the Cronbach alpha coefficient for the AQ Hostility subscale was .84 .

Simple Screening Instrument (SSI). The 16-item SSI (Center for Substance Abuse Treatment, 1994) is used to assess symptoms of alcohol and drug dependency and has been found to have very strong test-retest reliability in comparison with other screening instruments $(.97$ over a 72-hour interval). The accuracy of the SSI in detecting the presence of alcohol or drug dependence has also been found to be high (82\%) and higher than several other screening instruments (Peters et al., 2000). The items from this scale are not homogeneous regarding content; thus, internal consistency reliability was not computed.

Social Adjustment Scale Self-Report (SAS-SR). The 54-item SAS-SR (Weissman \& Bothwell, 1976) measures adaptive functioning in a variety of contexts. Of interest in this study are the Social and Leisure, Family, and Marital subscales, which are represented by 19 items. Validation studies have found both the internal consistency and 1-month test-retest reliability for the full scale to be .74, and support has also been found for a variety of forms of criterion and construct validity. In this study, the Cronbach alpha coefficient was .75.

\section{Procedure}

Instructors of various psychology courses provided students with the opportunity to receive extra credit in their courses by participating in this research project or in alternative activities. Students were provided anonymity regarding all of their questionnaire responses (i.e., names were not collected on the questionnaires, and the questionnaires were returned in sealed envelopes).

\section{RESULTS}

\section{Internal Consistency Reliability}

The internal consistency reliability of the FBQ-B was found to be similar to that of the original instrument, and it actually increased in the case of the Mother and Father Substance Abuse subscales even though the wording of the items was identical to that used in the original FBQ. The Cronbach alpha coefficients for each of the FBQ-B subscales along with the original FBQ coefficients reported by Melchert and Sayger (1998) are shown in Table 1.

\section{Construct-Related Validity}

The construct validity of the FBQ-B was examined through an examination of correlations between FBQ-B scores and various indicators of adjustment and distress in adulthood. On the basis 


\section{Mean Scores, Standard Deviations, and Internal Consistency Estimates of the Family Background Questionnaire-Brief (FBQ-B) and the Corresponding Original FBQ Subscales}

\begin{tabular}{|c|c|c|c|c|c|c|c|c|c|c|}
\hline \multirow[b]{3}{*}{ Subscale } & \multicolumn{4}{|c|}{ FBQ-B ${ }^{a}$} & \multicolumn{6}{|c|}{ Original FBQ } \\
\hline & \multirow{2}{*}{$\begin{array}{l}\text { No. of } \\
\text { Items }\end{array}$} & \multirow[b]{2}{*}{$M$} & \multirow[b]{2}{*}{ SD } & \multirow{2}{*}{$\begin{array}{c}\text { Cron. } \\
\alpha\end{array}$} & \multirow{2}{*}{$\begin{array}{l}\text { No. of } \\
\text { Items }\end{array}$} & \multicolumn{2}{|c|}{ Nonclinicalb } & \multicolumn{2}{|c|}{ Clinical $^{c}$} & \multirow{2}{*}{$\begin{array}{c}\text { Cron. } \\
\alpha\end{array}$} \\
\hline & & & & & & $M$ & SD & $M$ & $S D$ & \\
\hline Mother Responsiveness & 17 & 3.91 & 0.85 & .93 & $24^{d}$ & 4.17 & 0.74 & 3.31 & 1.04 & .94 \\
\hline Father Responsiveness & 17 & 3.54 & 0.93 & .93 & $24^{d}$ & 3.85 & 0.91 & 2.86 & 1.10 & .92 \\
\hline Mother Physical Abuse & 5 & 4.18 & 0.86 & .80 & 2 & 3.98 & 0.98 & 3.39 & 1.33 & .73 \\
\hline Father Physical Abuse & 5 & 4.27 & 0.79 & .79 & 2 & 3.89 & 1.04 & 3.13 & 1.41 & .81 \\
\hline Physical Neglect & 7 & 4.36 & 0.75 & 81 & 7 & 4.59 & 0.57 & 4.19 & 0.80 & .82 \\
\hline Sexual Abuse ${ }^{\circ}$ & 7 & - & - & - & 6 & - & - & - & - & - \\
\hline Mother Substance Abuse & 5 & 4.40 & 0.96 & .92 & 5 & 4.49 & 0.80 & 3.91 & 0.94 & .80 \\
\hline Father Substance Abuse & 5 & 3.87 & 1.30 & .93 & 5 & 4.09 & 1.09 & 3.44 & 1.19 & .85 \\
\hline Total & $62^{4}$ & 3.94 & 0.63 & .95 & 169 & 3.88 & 0.54 & 3.18 & 0.67 & .98 \\
\hline
\end{tabular}

Note. Cron. $\alpha=$ Cronbach's alpha.

a $N=384$ for the FBQ-B. ${ }^{\circ}$ The data for these scores included 517 nonclinical participants who were vocational, undergradu-

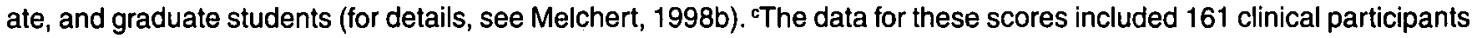
who were general mental health outpatients, general psychiatric inpatients, and substance-dependent outpatients (for details, see Melchert, 1998b). ${ }^{\top}$ The original FBQ included separate subscales for parental responsiveness and parental acceptance, but these were combined into a single parental responsiveness subscale in the FBQ-B. For comparison purposes, the items from the parental responsiveness and parental acceptance subscales in the original FBQ were also combined to compute these coefficients. ${ }^{\circ}$ The Sexual Abuse subscale items do not measure a unitary construct. Consequently, the mean and internal consistency reliability of these items was not computed. For informational purposes, frequency data for the FBQ-B item "Do you consider yourself to have been sexually abused as a child?" showed there were 89 participants $(23.2 \%$ out of 384$)$ who indicated that they had been sexually abused. Of these participants, $47.2 \%$ indicated that the abuse was minor, $11.2 \%$ indicated mild, $19.1 \%$ indicated moderate, and $22.5 \%$ indicated severe. The original FBQ did not include this item. 'Of the seven Sexual Abuse subscale items in the FBQ-B, six that assess frequency of abuse are scored differently (with Yes and No options followed by "If 'Yes,' how many times?" rather than a 5-point response scale); thus, these items are not included in the Total Scale.

of previous research with the original FBQ and numerous other studies (see Melchert, 1998a), negative correlations were expected (i.e., higher family of origin functioning was expected to be associated with lower indications of current adjustment and distress). The five outcome measures included participants' estimated levels of depression, anxiety, hostility, substance abuse, and social adjustment as assessed by the CES-D, CCAS, AQ Hostility subscale, SSI, and SAS-SR. As shown in Table 2, the correlations between these measures of adjustment and the FBQ-B subscales ranged from nonsignificant to moderately strong (in terms of the suggestions from Cohen, 1992, regarding the strength of effect sizes in which an $r$ of .10 is considered small, .30 medium, and .50 large). Although a small majority of the coefficients were statistically significant (at $p<.01$, two-tailed), nearly all were in the direction expected, namely, that adjustment scores indicating lower symptomatology and fewer signs of maladjustment were correlated with FBQ-B scores indicating higher levels of family functioning. In all cases but one (i.e., parental substance abuse and anxiety), the correlations were stronger between the adjustment measures and FBQ-B scores for mothers than they were between the adjustment measures and FBQ-B scores for fathers. The correlations were also strongest between the FBQ-B scores and the social adjustment scores in comparison with the other outcome measures except for the case of parental substance abuse, in which respondents' own reported substance use was the most strongly correlated with parental substance abuse scores. 
TABLE 2

\section{Correlations Between the Family Background Questionnaire-Brief (FBQ-B) and Adjustment Measures}

\begin{tabular}{lcccccccccc}
\hline & \multicolumn{10}{c}{ FBQ-B Subscales } \\
\cline { 2 - 8 } Adjustment Measure & MR & FR & MPA & FPA & PN & SA & MSA & FSA & Total \\
\hline Depression & -.24 & -.14 & -.15 & -.07 & -.16 & -.06 & -.12 & -.04 & -.22 \\
Anxiety & -.09 & -.06 & -.14 & -.04 & -.12 & .01 & -.04 & -.06 & -.09 \\
Hostility & -.25 & -16 & -.18 & -.10 & -.19 & .02 & -.17 & -.03 & -.24 \\
Substance abuse & -10 & -10 & -.08 & -.06 & -.11 & -.27 & -.27 & -.23 & -.18 \\
Social adjustment & -.34 & -.23 & -.29 & -.15 & -.31 & -.17 & -.15 & -.01 & -.34 \\
\hline
\end{tabular}

Note. Correlations greater than \pm .14 are significant at $p<.01$ (two-tailed). MR $=$ Mother Responsiveness; FR = Father Responsiveness; MPA = Mother Physical Abuse; FPA = Father Physical Abuse; $P N=$ Physical Neglect; $\mathrm{SA}=$ Sexual Abuse; MSA = Mother Substance Abuse; FSA = Father Substance Abuse.

aThe FBQ-B item "Do you consider yourself to have been sexually abused as a child?" (with a 5-point response scale ranging from No to Yes, severely) was used as a single indicator variable for Sexual Abuse.

Because the FBQ-B has restricted construct representativeness in comparison with the original FBQ, we also examined the correlation between the FBQ-B Total Scale score and the original FBQ Total Scale score to gain an indication of how the reduced content coverage of the significantly shorter FBQ-B affected the scores obtained. The Total Scale in the original FBQ includes 169 items; the Total Scale in the FBQ-B includes 62 items. The scores on these two versions of the Total Scale were correlated at .95 $(p<.001)$, suggesting that little is sacrificed in terms of the overall estimate of level of family functioning when the FBQ-B is used in place of the original instrument.

\section{Factor Analyses}

Confirmatory factor analyses (CFAs) were computed using the Amos 7.0 program (Arbuckle, 2006) to assess the fit of the sample data to the hypothesized structure of the FBQ-B subscales. We used CFAs rather than exploratory factor analyses because the scale structure of the instrument had already been established. We conducted the CFAs separately for mothers and fathers because the data were obtained with reference to two different populations (i.e., respondents' mothers vs. respondents' fathers). In addition, "Do you consider yourself to have been sexually abused as a child?" (with a 5-point response scale ranging from No to Yes, severely) was included in the analysis as a single indicator variable for sexual abuse. This was the only item from this subscale that functioned in the same manner as the items from the other subscales; the other responses to Sexual Abuse subscale items were highly skewed and had high kurtosis because of the relatively low reported frequency of sexual contact with various categories of individuals. In addition, these other Sexual Abuse subscale items were heterogeneous in content as they asked about sexual contact with different categories of individuals such that a response to one item was not predictive of responses to the other items in the subscale. For these reasons, in the CFA model, the sexual abuse variable was assessed by a single indicator. This is a limitation of the model, although it does provide a more complete representation of the constructs assessed.

To provide a stronger test of the fit of the data to the hypothesized scale structure, we compared differences between nested models using a one-factor, two-factor, and the hypothesized five-factor models. The one-factor model represented a global general family functioning variable (i.e., all items loaded on to one latent variable), the two-factor model represented a global child maltreatment variable along with a parental substance abuse variable, and the 
five-factor model represented the theoretical rationale for the FBQ-B previously described (with eight subscales for parental responsiveness, parental physical abuse, physical neglect, sexual abuse, and parental substance abuse). We followed the suggestions of Raykov and Penev (1998) in using a $90 \%$ confidence interval (CI) with the root mean square error of approximation (RMSEA) to decide whether two of the nested models were significantly different. A 90\% CI provides a more conservative test for detecting true differences than does the usual 95\% CI. If the RMSEA 90\% CIs between two nested models are found to overlap, then the differences in model fit are not considered statistically significant. A number of fit indices are reported. We relied more on the RMSEA because this index, in comparison with several typical indices of model fit, has been the only one found not to be influenced by the number of indicators, number of factors, and sample sizes (Cheung and Rensvold, 2002). Browne and Cudeck (1993) have suggested that RMSEA values of less than .05 indicate a close fit, values of less than .08 indicate a reasonable or near fit, and values greater than .10 indicate a poor fit, whereas Hu and Bentler (1999) have suggested that RMSEA values of less than .06 can be evaluated as representing a good fit.

The chi-square value for all of the models was significant, indicating a statistically significant difference between the observed and specified models. The chi-square analysis often results in statistical significance for large samples, and conse(puently, it is not taken as an indicator of poor fit in practical terms (Bentler, 1990; Fassinger, 1987). More important for our purposes were the results from the other indices. As shown in Table 3, the goodness-offit indicators for the five-factor model on the basis of the theoretical rationale of the FBQ-B resulted in the strongest fit, and the RMSEA $90 \% \mathrm{CI}$ for this model did not overlap with those of the other models. The RMSEA value of .058 represented a reasonably good fit, whereas the comparative fit index and Tucker-Lewis index values also suggested a reasonably well fitting model. In addition, all the estimated factor loadings in the five-factor model were found to be statistically significant (all $p s<.001$ ) and meaningful (standardized factor loadings ranged from .32 to .98 on their respective subscales).

\section{DISCUSSION}

An attempt was made to develop a shorter version of the rather lengthy original FBQ so that a more efficient alternative would be available for various clinical and research purposes. The reported results suggest that the brief version of the instrument that assesses parental respon-

TABLE 3

\section{Goodness-of-Fit Indicators for the Family Background Questionnaire-Brief (FBQ-B) Models}

\begin{tabular}{lcccccc}
\hline \hline Model & $\chi^{2}$ & $d f$ & CFI & TL.I & RMSEA & 90\% Cl \\
\hline Mother responses & & & & & & \\
One global factor & $1,855.91^{*}$ & 542 & .805 & .706 & .086 & $.081-.090$ \\
Two-factor & $1,519.07^{*}$ & 547 & .856 & .843 & .073 & $.069-.078$ \\
Five-factor (FBQ-B model) & $1,292.19^{*}$ & 541 & .886 & .874 & .065 & $.060-.069$ \\
Father responses & & & & & & \\
$\quad$ One global factor & $1,701.64^{*}$ & 538 & .827 & .809 & .081 & $.077-.085$ \\
Two-factor & $1,368.32^{*}$ & 544 & .877 & .866 & .068 & $.063-.072$ \\
Five-factor (FBQ-B model) & $1,137.03^{*}$ & 539 & .911 & .902 & .058 & $.053-.063$ \\
\hline
\end{tabular}

Note. CFI = comparative fit index; TLI = Tucker-Lewis index; RMSEA = root mean square error of approximation; $\mathrm{Cl}=$ confidence interval.

${ }^{*} p<.001$. 
siveness, child maltreatment, and parental substance abuse will provide reliable scores that may be useful for these purposes. The internal consistency of the various FBQ-B subscales suggests moderate to strong reliability, the correlations found between the FBQ-B scores and various measures of distress and adjustment were all in the hypothesized direction even though many of them were statistically nonsignificant, and the results from the CFAs provide support for the FBQ-B's hypothesized scale structure. Given the consistency of the reliability and validity results between the FBQ and the FBQ-B, the significantly reduced length of the FBQ-B increases its utility as a screening instrument for gaining information about important aspects of family history. However, this gain in utility comes with a sacrifice in the construct representativeness of the FBQ-B, because the content of this brief version of the instrument focuses on a limited number of variables in comparison with the original FBQ. The FBQ-B has been designed to capture the most important aspects of family of origin functioning, and the .95 correlation between scores on the Total Scale for the original instrument and the Total Scale for the FBQ-B suggests that little is lost when the brief version is used in place of the original version to obtain overall estimates of level of family of origin functioning. The original FBQ will be the best choice to use, however, when a more comprehensive assessment of the full range of aspects of family functioning is needed.

Whereas the FBQ-B may provide reliable scores regarding various aspects of family history, users of the instrument must consider the complex issues surrounding the interpretation of the information and scores provided. As previously mentioned, it is impossible to retrospectively measure characteristics of adult's family of origin experiences. Users of the FBQ-B must remember that they are asking respondents about their memories and perceptions of various childhood experiences, not about characteristics of the actual experiences themselves. Child maltreatment and family dysfunction are complicated constructs, and substantial variation often exists in how these constructs are defined across individuals and sociocultural groups. A substantial historical effect tends to exist such that individuals within different age cohorts often define these constructs in quite different ways (Erickson \& Egeland, 2002). Individual differences in reliability of autobiographical memory, cognitive appraisal of childhood events, embarrassment surrounding abusive childhood experiences, rapport with an interviewer or instrument administrator, and a variety of other psychological and sociocultural variables can greatly influence how childhood events are recalled, perceived, and reported. Therefore, both the collection and interpretation of family history data involve complicated assessment issues requiring substantial clinical skill and expertise. Family and childhood history are very important research and clinical topics, so these variables are assessed frequently. In all cases, however, the interpretation of test scores needs to proceed cautiously, with full awareness of the range of factors that can affect the meaning of the information obtained.

Considering the evidence regarding the adverse outcomes that can be associated with unresponsive parenting, child maltreatment, and parental substance abuse, perhaps more efficient family history instruments will increase the research and clinical attention that is given to these important issues. Increasing the ability to prevent these risk factors from occurring, as well as ameliorate their adverse consequences once they do occur, is deserving of the best research and clinical efforts.

\section{REFERENCES}

Arbuckle, J. L. (2006). Amos 7.0 user's guide. Chicago: SPSS.

Belsky, J. (1980). Child maltreatment: An ecological integration. American Psychologist, 35, 320-335.

Bentler, P. M. (1990). Comparative fit indexes in structural models. Psychological Bulletin, 107, 238-246. 
Bronfenbrenner, U. (1979). The ecology of human development: Experiments by nature and design. Cambridge, MA: Harvard University Press.

Browne, M. W., \& Cudeck, R. (1993). Alternative ways of assessing model fit. In K. A. Bollen \& J. S. Long (Eds.), Testing structural equation models (pp. 136-162). London: Sage.

Buss, A. H., \& Perry, M. (1992). The Aggression Questionnaire. Journal of Personality and Social Psychology, 63, 452-459.

Center for Substance Abuse Treatment. (1994). Simple screening instruments for outreach for alcohol and other drug abuse and infectious diseases (Treatment Improvement Protocol No. 11). Rockville, MD: Author.

Cheung, G. W., \& Rensvold, R. B. (2002). Evaluating goodness-of-fit indexes for testing measurement invariance. Structural Equation Modeling, 9, 233-255.

Cicchetti, D., \& Lynch, M. (1993). Toward an ecological/transactional model of community violence and child maltreatment: Consequences for children's development. Psychiatry: Interpersonal and Biological Processes, 56, 96-118.

Cohen, J. (1992). A power primer. Psychological Bulletin, 112, 155-159.

Costello, C. G., \& Comrey, A. L. (1967). Scales for measuring depression and anxiety. Journal of Psychology: Interdisciplinary and Applied, 66, 303-313.

Erickson, M. F., \& Egeland, B. (2002). Child neglect. In J. E. B. Myers, L. Berliner, J. Briere, C. T. Hendrix, C. Jenny, \& T. A. Reid (Eds.), The APSAC handbook on child maltreatment (2nd ed., pp. 3-20). Thousand Oaks, CA: Sage.

Fassinger, R. E. (1987). Use of structural equation modeling in counseling psychology research. Journal of Counseling Psychology, 34, 425-436.

Grossmann, K. E., Grossmann, K., \& Waters, E. (Eds.). (2006). Attachment from infancy to adulthood: The major longitudinal studies. New York: Guilford Press.

Hart, S. N., Brassard, M. R., Binggeli, N. J., \& Davidson, H. A. (2002). Psychological maltreatment. In J. E. B. Myers, L. Berliner, J. Briere, C. T. Hendrix, C. Jenny, \& T. A. Reid (Eds.), The APSAC handbook on child maltreatment (2nd ed., pp. 79-103). Thousand Oaks, CA: Sage.

Hu, L., \& Bentler, P. M. (1999). Cutoff criteria for fit indexes in covariance structure analysis: Conventional criteria versus new alternatives. Structural Equation Modeling, 6, 1-55.

Kelley, S. J. (2002). Child maltreatment in the context of substance abuse. In J. E. B. Myers, L. Berliner, J. Briere, C. T. Hendrix, C. Jenny, \& T. A. Reid (Eds.), The APSAC handbook on child maltreatment (2nd ed., pp. 105-117). Thousand Oaks, CA: Sage.

Kempe, C. H., Silverman, F. N., Steele, B. F., Droegemueller, W., \& Silver, H. K. (1962). The battered-child syndrome. The Journal of the American Medical Association, 181, 17-24.

Maccoby, E. E. (1984). Socialization and developmental change. Child Development, 55, 317-328.

Melchert, T. P. (1998a). A review of instruments for assessing family history. Clinical Psychology Review, 18, $163-187$.

Melchert, T. P. (1998b). Testing the validity of an instrument for assessing family of origin history. Journal of Clinical Psychology, 54, 863-876.

Melchert, T. P., \& Sayger, T. V. (1998). The development of an instrument for measuring memories of family of origin characteristics. Educational and Psychological Measurement, 58, 99-118.

Mikulincer, M., \& Shaver, P. R. (2007). Attachment in adulthood: Structure, dynamics, and change. New York: Guilford Press.

National Center on Child Abuse and Neglect. (1981). National study of the incidence and severity of child abuse and neglect: Study findings. Washington, DC: U.S. Department of Health and Human Services, Office of Human Development Services, Administration on Children, Youth and Families, Children's Bureau.

Parker, G., Tupling, H., \& Brown, L. B. (1979). A parental bonding instrument. British Journal of Medical Psychology, 52, 1-10.

Peters, R. H., Greenbaum, P. E., Steinberg, M. L., Carter, C. R., Ortiz, M. M., Fry, B. C., \& Valle, S. K. (2000). Effectiveness of screening instruments in detecting substance use disorders among prisoners. Journal of Substance Abuse Treatment, 18, 349-358.

Radloff, L. S. (1977). The CES-D Scale: A self-report depression scale for research in the general population. Applied Psychological Measurement, 1, 385-401.

Raykov, T., \& Penev, S. (1998). Nested structural equation models: Noncentrality and power of restriction test. Structural Equation Modeling, 5, 229-246.

Reid, J., Macchetto, P., \& Foster, S. (1999). No safe haven: Children of substance-abusing parents. New York: National Center on Addiction and Substance Abuse at Columbia University. 
Santor, D. A., \& Coyne, J. C. (1997). Shortening the CES-D to improve its ability to detect cases of depression. Psychological Assessment, 9; 233-243.

Scannapieco, M., \& Connell-Carrick, K. (2005). Understanding child maltreatment: An ecological and developmental perspective. New York: Oxford University Press.

Schwarz, J. C., \& Zuroff, D. C. (1979). Family structure and depression in female college students: Effects of parental conflict, decision-making power, and inconsistency of love. Journal of Abnormal Psychology, 88, 398-406.

Sedlak, A. J., \& Broadhurst, D. D. (1996a). Executive summary of the third national incidence study of child abuse and neglect. Retrieved July 25, 2007, from the Child Welfare Information Gateway Web site: http://www.childwelfare.gov/pubs/statsinfo/nis3.cfm

Sedlak, A. J., \& Broadhurst, D. D. (1996b). Third national incidence study of child abuse and neglect. Washington, DC: U.S. Government Printing Office.

Substance Abuse and Mental Health Services Administration. (2007). Results from the 2006 national survey on drug use and health: National findings (Office of Applied Studies, NSDUH Series H-32, DHHS Publication No. SMA 07-4293). Rockville, MD: Author.

Touliatos, J., Perlmutter, B. F., \& Straus, M. A. (Eds.). (2001). Handbook of family measurement techniques. Thousand Oaks, CA: Sage.

Weissman, M. M., \& Bothwell, S. (1976). Assessment of social adjustment by patient self-report. Archives of General Psychiatry, 33, 1111-1115.

Wekerle, C., \& Wall, A.-M. (2002). Introduction: The overlap between relationship violence and substance abuse. In. C. Wekerle \& A.-M. Wall (Eds.), The violence and addiction equation: Theoretical and clinical issues in substance abuse and relationship violence (pp. 1-24). New York: Brunner/Routledge.

Widom, C. S., \& Morris, S. (1997). Accuracy of adult recollections of childhood victimization, Part 2: Childhood sexual abuse. Psychological Assessment, 9, 34-46. 